\title{
Bending cyclic behavior and scatter-band analysis of aluminum alloys under beneficial and detrimental conditions through high- cycle fatigue regime
}

\author{
Mohammad Azadi \\ Faculty of Mechanical Engineering, Semnan University, Semnan, Iran \\ m_azadi@semnan.ac.ir, bttp:/ /orcid.org/0000-0001-8686-8705 \\ Hanieh Aroo \\ Faculty of Mechanical Engineering, Semnan University, Semnan, Iran
}

\begin{abstract}
This article presents the bending fatigue behavior and the scatterband analysis of aluminum alloys under beneficial conditions of nano-clayparticles and heat-treating, compared to detrimental conditions of the mechanical stress and the corrosion. Moreover, the sensitivity analysis was also done on the stress level, the pre-corrosion phenomenon, the addition of nano-particles, and applying the heat treatment on the high-cycle bending fatigue lifetime of the aluminum-silicon alloy. For this objective, gravity and stir-casting processes were done for aluminum alloy and nano-clay-composite specimens and then, standard samples were machined from initial casted cylinders. Furthermore, rotary fatigue tests were performed under cyclic bending loadings, through the high-cycle fatigue regime. Some samples were pre-corroded in the sulfuric acid for 200 hours. Based on the sensitivity analysis on experimental data by the Minitab software, the obtained results indicated that the stress level was the effective parameter on the fatigue lifetime. The meaningful regression model was calculated and calibrated on the logarithmic scale of the fatigue lifetime. Then, the second sensitive parameter was demonstrated as the pre-corrosion, which caused significant degradation of fatigue properties in the material. The last-ranked factor was related to nano-particles for the beneficial effect on the improvement of the high-cycle fatigue lifetime. The scatter-band analysis illustrated that nanoparticles and heat-treating changed the scattering behavior of experimental data.
\end{abstract}

KEYwORDS. Bending fatigue; Scatter-band analysis; Aluminum alloy; Nanoclay-particles; Heat-treating; Corrosion.

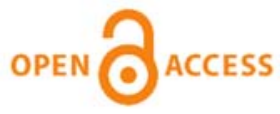

Citation: Azadi, M., Aroo, H., Bending fatigue behavior and scatter-band analysis of aluminum alloys under beneficial conditions of nano-clay-particles and heat-treating, compared to detrimental conditions of mechanical stress and corrosion, Frattura ed Integrità Strutturale, 58 (2021) 272-281.

Received: 19.08 .2021

Accepted: 27.08.2021

Published: 01.10.2021

Copyright: (C) 2021 This is an open access article under the terms of the CC-BY 4.0, which permits unrestricted use, distribution, and reproduction in any medium, provided the original author and source are credited. 


\section{INTRODUCTION}

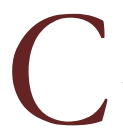

orrosion damages are one problem in aluminum-based mechanical structures. One case study is the cylinder head in a diesel engine, which is arrested by the corrosive fuel environment besides cyclic mechanical loadings. Therefore, knowing the corrosion-fatigue behavior of the material could be useful for designer engineers [1-2]. Moreover, the improvement in the corrosion-fatigue lifetime of components is to be noticed in the automotive industry. Various ways to increase the service lifetime are heat treatments, in addition to the recent knowledge edge of nano-particles [3].

In this field of study, different articles have been widely published until now. Guerin et al. [4] investigated the corrosionfatigue lifetime of 2050 aluminum-copper-lithium alloy, in the chloride solution. They indicated that T34 and T84 states were respectively susceptible to inter and intragranular corrosion in the material. Moreover, the fatigue lifetime of the T34 heat-treated alloy was most affected by the fatigue-corrosion phenomena. Since the propagation of the intergranular corrosion was assisted by cyclic mechanical loading. Chen et al. [5] found the effect of the pre-deformation on the precorrosion multiaxial fatigue behaviors of 2024-T4 aluminum alloy. Their results illustrated a reduction percentage of precorroded fatigue lifetime with the pre-deformation level due to the pitting marks caused by the corrosion. They showed that the combination of pre-deformation and pre-corrosion was more detrimental than that of either one acting separately. Rodriguez et al. [6] performed a study on corrosion effects on the low-cycle fatigue behavior of dissimilar friction stir welding of high-strength aluminum alloys. The immersion in $3.5 \% \mathrm{NaCl}$ for various exposure times resulted in the localized corrosion damage in the thermo-mechanically affected and heat-affected zones. They observed corrosion damages such as general pitting, pit clustering, and exfoliation, which caused a decrease in the fatigue lifetime. Azadi et al. [2] compared the high-cycle fatigue lifetime in un-corroded and corroded piston aluminum alloys, within the diesel engine application. Their results showed higher weight losses for 200 hours immersion times, which resulted in the lifetime decrease in pre-corrosive samples.

In the literature review, almost all works were presented through qualitative analysis. In only rare articles such as Azadi et al. [3], the quantitative analysis was performed on fatigue and corrosion-fatigue phenomena of materials. Based on a claimed novelty in this research, the sensitivity analysis of the stress, the pre-corrosion, the addition of nano-particles, and the heat treatment was done on the fatigue lifetime of aluminum alloys. As another novelty, the corrosive environment was salts or acids, in the literature review. However, in this article, the influence of sulfuric acid was considered due to the diesel fuel and the combustion products. The third novelty is to analyze the scatter-band for fatigue experimental data for different conditions of studied materials. It should be mentioned that this research is an extended article from the previously published literature [7]. Notably, the third novelty based on the scatter-band analysis of experimental data is the extended text for fatigue and corrosion-fatigue testing.

\section{MATERIALS AND EXPERIMENTS}

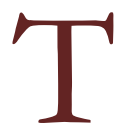

he fatigue and corrosion-fatigue behaviors of the AlSi12CuNiMg aluminum alloy (the European name of the material: AC48000) were studied in this research. This aluminum-silicon alloy has been widely used for the engine piston in the automotive industry. The chemical composition was $12.70 \mathrm{wt} . \% \mathrm{Si}, 1.16 \mathrm{wt} . \% \mathrm{Cu}, 1.00 \mathrm{wt.} \% \mathrm{Mg}, 0.80$ wt. $\% \mathrm{Ni}, 0.56$ wt. $\% \mathrm{Fe}$ and the remainder was the aluminum element. In order to fabricate the metal-based nano-composite, $1 \mathrm{wt} . \%$ of nano-clay-particles was added to the aluminum melt, during the stir-casting technique.

For this objective, melting of aluminum bars was done firstly at $700^{\circ} \mathrm{C}$ for about $2 \mathrm{~h}$. Then, pre-heated nano-particles at $400^{\circ} \mathrm{C}$ were added to the melt. After $20 \mathrm{~min}$ of stirring, a steady condition was obtained for the melt and cylindrical samples were cast in a cast-iron mold. In this regard, more details could be found in the literature [8]. It should be noted that the expectation of adding nano-clay-particles to aluminum alloys is to increase the hardness, strength, and fatigue lifetime. Such an advantage by the nanotechnology could be utilized in the engine piston, which is working under high-temperature cyclic loadings. Since the clay type as a ceramic (metal oxides) was considered and selected for the nano-particle, the strength and the low-cycle fatigue lifetime of the material would enhance, especially at high temperatures [8]. Similar components could be fabricated from such a nano-composite, where high temperatures occur.

For the corrosion study, the acid amount of $0.00235 \%$ from the sulfuric acid was considered and a pre-corrosion process was performed for 200 hours before fatigue testing, to illustrate the corrosion effect on the fatigue lifetime of materials. Then, rotary high-cycle bending fatigue testing was performed on standard samples, either from the base material, the corroded sample, the reinforced specimen, and the corroded nano-composite. The dimension of the cylindrical specimen was $76 \mathrm{~mm}$ of the total length, $18 \mathrm{~mm}$ of the gauge length, and also $4 \mathrm{~mm}$ and $9 \mathrm{~mm}$ of the smallest and largest diameters, 
respectively. It should be noted that fatigue testing was carried out based on the ISO-1143:2010 standard [9], under 4 stress levels by the SFT-600 rotary bending fatigue machine. These bending stress levels were 120, 150, 180, and $210 \mathrm{MPa}$.

More details for the fabrication of the studied materials could be found in the literature by Aroo et al. [1], Azadi et al. [3], Rezanezhad et al. [10], and Zolfaghari et al. [11]. In addition, more details of fatigue testing and the geometry of standard cylindrical samples could be followed in the literature by Parast et al. [12], Sharifi et al. [13], and Khisheh et al. [14].

After testing, a regression curve-fitting process was done for the sensitivity analysis on experimental data. This job was performed in the MINITAB software, using regression analysis. In this study, the value of the risk level was usually 0.05. Therefore, the P-Value in the sensitivity analysis should be less than 0.05 to claim that one input parameter was sensitive and effective on outputs. Moreover, higher F-Value amounts mean higher effects of inputs on outputs. In this case of study, inputs included the stress, the pre-corrosion, the addition of nano-particles, and the heat treatment. Then, the output was the fatigue lifetime in both normal and logarithmic scales.

To present data in a better manner, some abbreviations were used, which could be seen in Tab. 1. These abbreviations were used for different samples and various types of fatigue testing.

\begin{tabular}{ccc}
\hline No. & Abbreviations & Explanations \\
1 & PF & Pure bending fatigue testing \\
2 & CF & Corrosion-fatigue testing with pre-corroded samples \\
3 & AlSi_N0_T0 & Aluminum-silicon alloy \\
4 & AlSi_N1_T0 & Aluminum-silicon alloy, reinforced with nano-clay-particles \\
5 & AlSi_N1_T6 & Aluminum-silicon alloy, reinforced with nano-clay-particles and the heat treatment \\
\hline
\end{tabular}

Table 1: Abbreviations for tests and samples in this study.

Usually, experimental fatigue data have high scattering, especially in the high-cycle fatigue regime. Therefore, the fatigue lifetime of materials is described by statistical functions such as Weibull or Normal [15-17]. For these distribution functions, the averaged value $(\mu)$ and the standard deviation $(\sigma)$ are considered for recorded data.

To analyze the scatter-band of fatigue experimental data, for each lifetime $(x)$, there are several models [17]. However, in this research, Eq. (1) was utilized for the scatter-band analysis, which could be written as follows [16,17],

$$
z=\frac{x-\mu}{\sigma}
$$

where the $₹$ value could be found from the literature $[16,17]$ and the confidence level. In this research, the confidence level was considered as 85,90 , and $95 \%$ for the Normal distribution function. When the confidence level increases, the scatterband will be wider. It should be noted that the $₹$ value is 1.44, 1.65, and 1.96 when the confidence level is 85, 90, and 95\%, respectively [16,17]. Finally, the scatter-band could be written as $\mu=N \pm z \sigma$, where $N$ is the fatigue lifetime at each stress level.

\section{RESUlTS AND DisCUSSION}

$\mathrm{F}$ ig. 1 presents the curve of the stress versus the fatigue lifetime of studied materials, as a first result. It should be noted that obtained results in Fig. 1 are for both fatigue and corrosion-fatigue phenomena. As another note in this figure, the averaged value of lifetime data was considered. The variation of the fatigue lifetime was also studied in the section that is related to the scatter-band analysis. Therefore, the standard deviation is not shown in Fig. 1, in order to avoid data cluttering in the chart. Considering a logarithmic function, curve-fitting between the stress and the fatigue lifetime was properly carried out by high values of the coefficient of determination $\left(\mathrm{R}^{2}\right)$, higher than $93 \%$.

As it could be seen from obtained results in Fig. 1, the slope of the curves under fatigue and corrosion-fatigue testing was almost similar for one type of material. Moreover, the heat-treated nano-composite had a higher fatigue lifetime, compared to the base material, especially for the low-cycle fatigue regime or under higher stress levels. However, only the addition of 
nano-particles to the aluminum matrix had a reverse effect and decreased the fatigue lifetime. Such trends could be also for the corrosion-fatigue lifetime of studied materials. In other words, the slope of the curves for one type of testing was different for all types of studied materials. It means that the addition of nano-clay-particles and the heat treatment changed the slope of the stress-lifetime curve.

Comparing results in Fig. 1 showed that the corrosion effect on the fatigue lifetime was negative and detrimental and therefore, the degradation of the material performance occurred, either in different types of alloys. Under high-stress levels and through the low-cycle fatigue regime, the corrosion-fatigue lifetime of aluminum-silicon alloys (reinforced with nanoparticles and the heat treatment) increased, compared to that of aluminum-silicon alloys, as also claimed by Rezanezhad et al. [10]. Considering obtained results for fatigue and corrosion-fatigue testing for comparison, the corrosion-fatigue lifetime was less than the fatigue lifetime in all cased, as also reported by Guerin et al. [4], Chen et al. [5], Rodriguez et al. [6], and Azadi et al. [1].

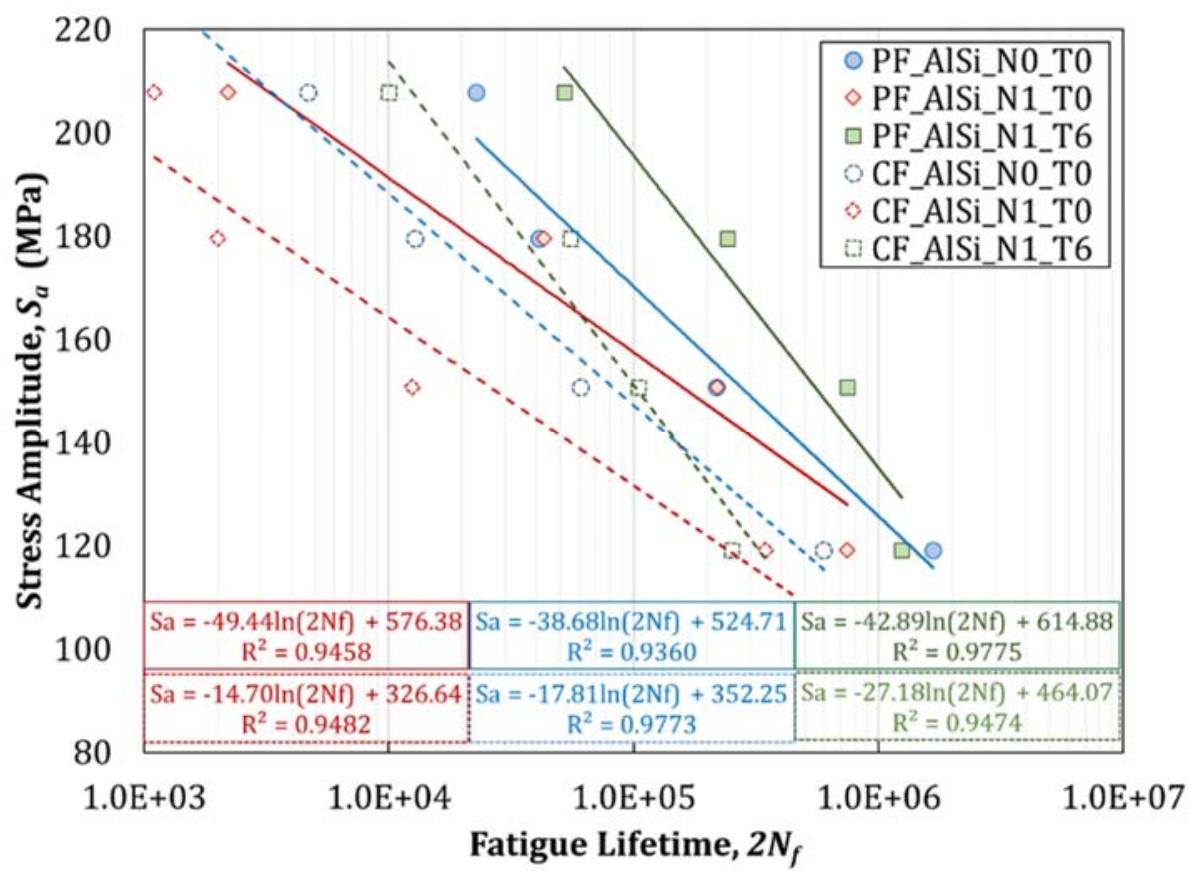

Figure 1: The curve of the stress amplitude $\left(S_{a}\right)$ versus twice times of the fatigue and corrosion-fatigue lifetimes $\left(2 N_{f}\right)$ in a logarithmic scale, considering the averaged value.

The main objective of this article was the sensitivity analysis of inputs on outputs. The obtained results from the regression analysis on experimental data could be found in Tab. 2, respectively for normal and logarithmic scales. For this order, the coefficient of determination $\left(\mathrm{R}^{2}\right)$ was calculated as 42.78 and $86.98 \%$, respectively. This means that the logarithmic scale of the fatigue lifetime had a meaningful trend, compared to the normal scale. It should be noted that the P-value of the regression analysis was less than 0.05 and therefore, the sensitivity analysis was meaningful for both scales.

Based on the P-value in the normal scale of the fatigue lifetime, the stress and the pre-corrosion were effective parameters, since they had a P-value lower than 0.05. However, the effect of both reinforcements was not significant on the fatigue lifetime of studied materials. Considering the F-value, the effect of the stress was higher than the pre-corrosion influence of the fatigue performance of the material.

Besides, according to the P-value in the normal scale of the fatigue lifetime, all input parameters were effective on the fatigue performance of the material. The F-value indicated that the most effective parameter was the stress, the pre-corrosion, the heat treatment, and lastly, nano-particles. As another observation from these results, the influence of beneficial conditions (the heat treatment and nano-particles) was less than that of detrimental conditions (the stress, the pre-corrosion) on the fatigue lifetime. The applied stress was the first factor, which had detrimental effects on the fatigue lifetime. The other harmful parameter is the pre-corrosion, since the additional damage like pits decreased the fatigue lifetime, besides the effect of the applied stress. These corrosion pits could be a location for the stress concentration and the potential region for the crack initiation, sooner than the condition of having no pre-corrosion. The heat treatment was the third factor, which had 
beneficial effects on the fatigue lifetime. Since the hardness of the material increased by heat-treating, fatigue properties would improve, especially through the high-cycle fatigue regime. The last-ranked useful parameter was nano-particles. However, this factor could be a detrimental condition. Since if there was any agglomeration in the microstructure, they could be a potential location for the stress concentration and the crack initiation.

\begin{tabular}{ccccc}
\hline \multirow{2}{*}{ Parameter } & \multicolumn{2}{c}{ The normal scale of the fatigue lifetime } & The logarithmic scale of the fatigue lifetime \\
\cline { 2 - 5 } & F-Value & P-Value & F-Value & P-Value \\
Regression & 12.71 & 0.000 & 113.07 & 0.000 \\
Stress & 37.34 & 0.000 & 216.82 & 0.000 \\
Pre-corrosion & 11.32 & 0.001 & 72.76 & 0.000 \\
Nano-particles reinforcement & 1.81 & 0.184 & 22.39 & 0.000 \\
Heat treatment reinforcement & 2.04 & 0.158 & 62.61 & 0.000 \\
\hline
\end{tabular}

Table 2: The sensitivity analysis for normal and logarithmic scales of the fatigue lifetime.

To find the qualitative trend of input parameters on the output, Fig. 2 is presented. Based on these results, as expected, by increasing the stress, the fatigue lifetime decreased. However, by the addition of nano-particles, the fatigue lifetime reduced. By the heat treatment, the fatigue lifetime of the material enhanced. Finally, by the pre-corrosion, the degradation occurred in the material performance. As a note, the stress was a continuous parameter and therefore, a continuous line was used in the regression analysis. For other parameters, data were discrete and two points could be observed for each state.

Increasing the fatigue lifetime of aluminum alloys by the reinforcement was also reported by Rezanezhad et al. [10], Sharifi et al. [13], and Khisheh et al. [14], which could be claimed as an agreement with obtained results in this research. The reason for such an improvement was due to the microstructural changes in the microstructure of the aluminum alloy. The heat treatment and the addition of nano-particles led to a decrease in the size of the grain in the material microstructure. Moreover, checking the interaction effect of input parameters on the logarithmic scale of the fatigue lifetime indicated that since no crossed lines could be observed; therefore, no interaction of parameters could be claimed on the fatigue performance of studied materials.

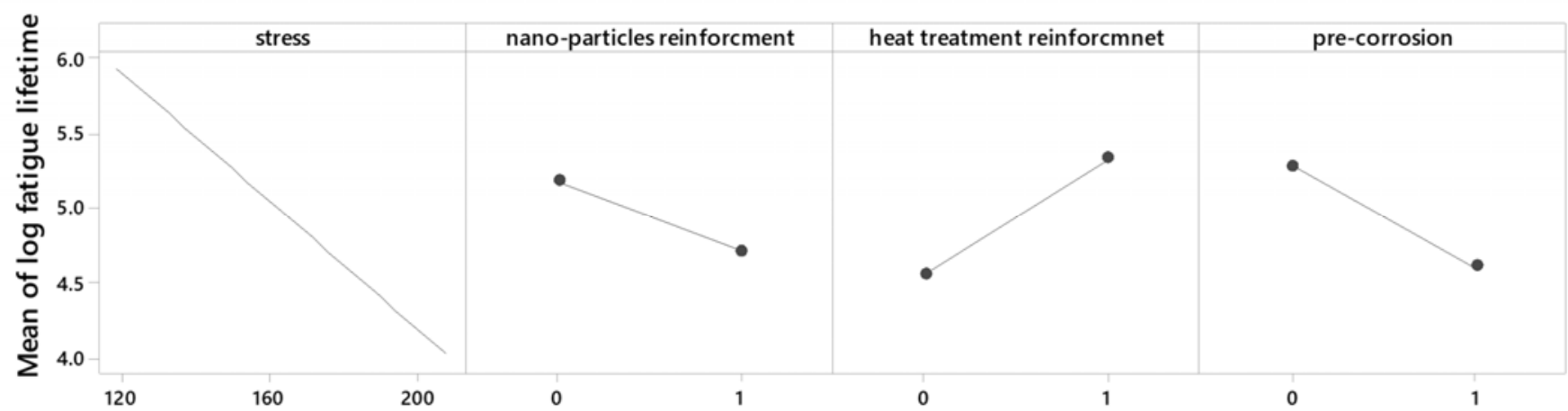

Figure 2: The qualitative trend of input parameters on the logarithmic scale of the fatigue lifetime.

In Fig. 3, the scatter-band of fatigue data is presented for the aluminum alloy, the nano-composite, and the heat-treated nano-composite, on a logarithmic scale and for different confidence levels. Similar to these results, Fig. 4 depicts the scatterband of corrosion-fatigue data for studied materials.

Obtained results indicated that the fatigue scatter-band of the nano-composite was narrower than those of two other materials. However, the heat-treated nano-composite had a wider fatigue scatter-band, especially in the high-cycle fatigue regime. In other words, the heat treatment led to scattered experimental data. Such a discussion could not be claimed for corrosion-fatigue data and the scatter-band was almost similar for all studied materials. As another note, the aluminum alloy had a homogeneous scatter in both fatigue and corrosion-fatigue phenomena through both low- and high-cycle fatigue regimes. However, adding nano-particles and the heat treatment caused changes in this behavior through low- and highcycle fatigue regimes. The reason could be the formed defects during the stir-casting process, which had higher numbers of parameters, compared to the gravity casting of the aluminum alloy. 
(a)

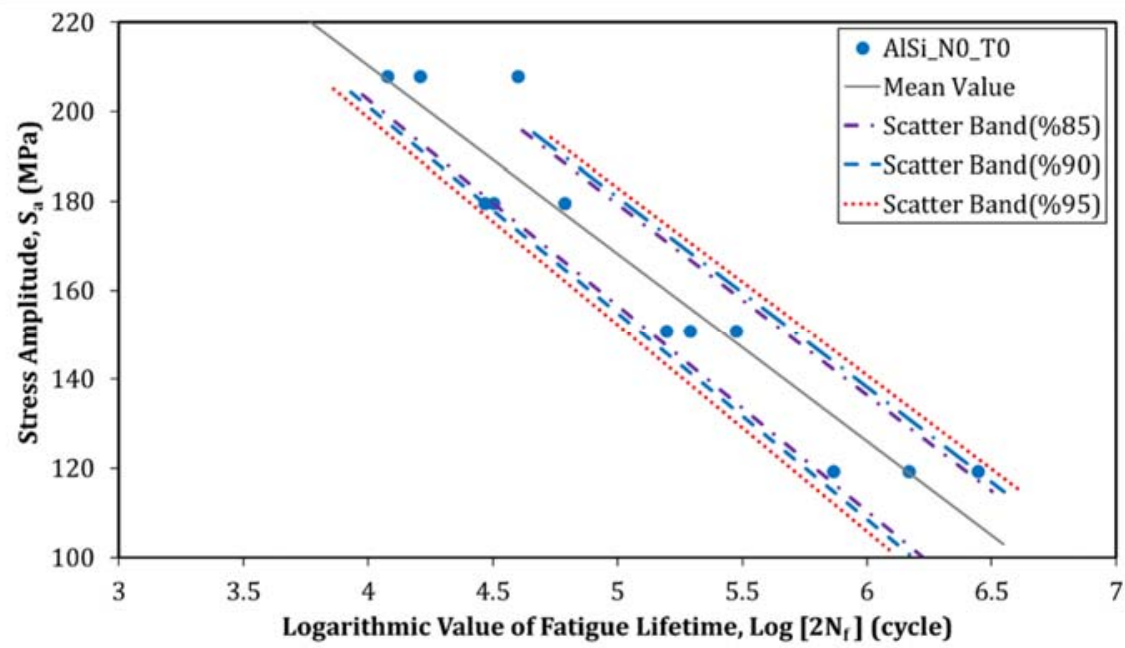

(b)

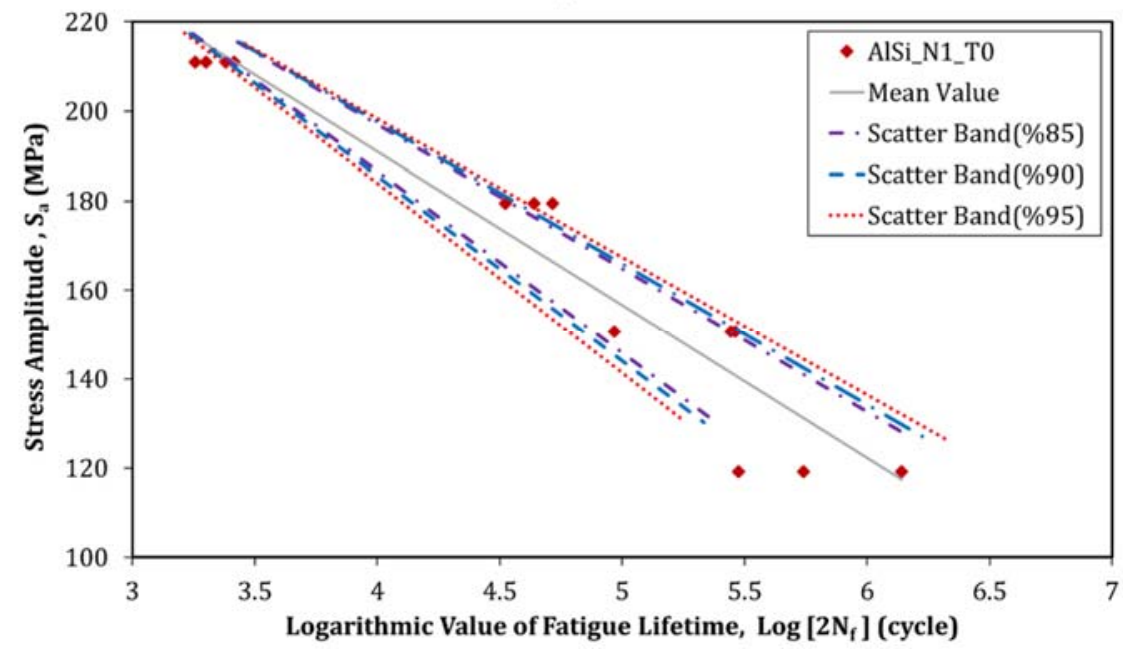

(c)

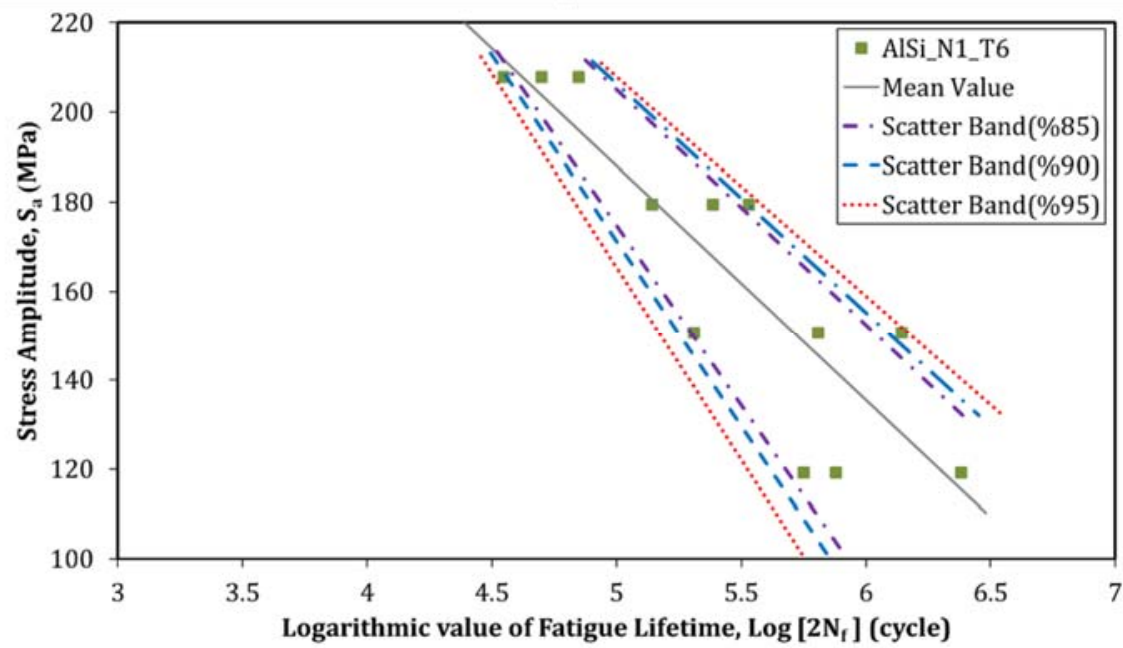

Figure 3: The scatter-band for fatigue data of (a) the aluminum alloy, (b) the nano-composite, and (c) the heat-treated nano-composite (Note: The horizontal axis includes the logarithmic value of the fatigue lifetime). 
(a)

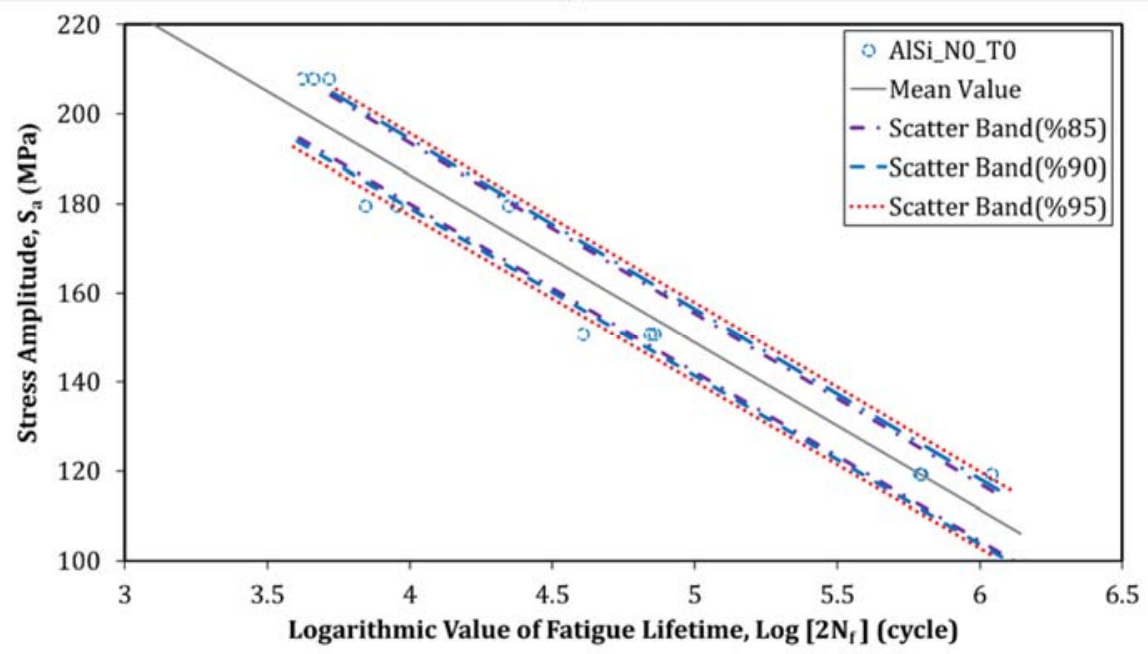

(b)

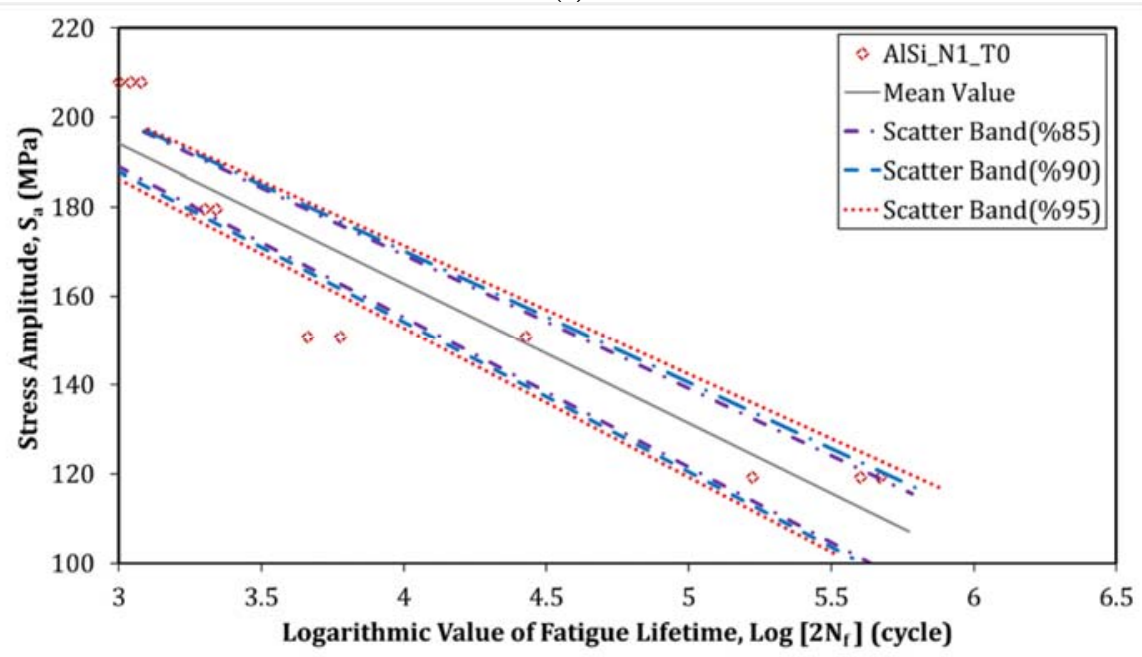

(c)

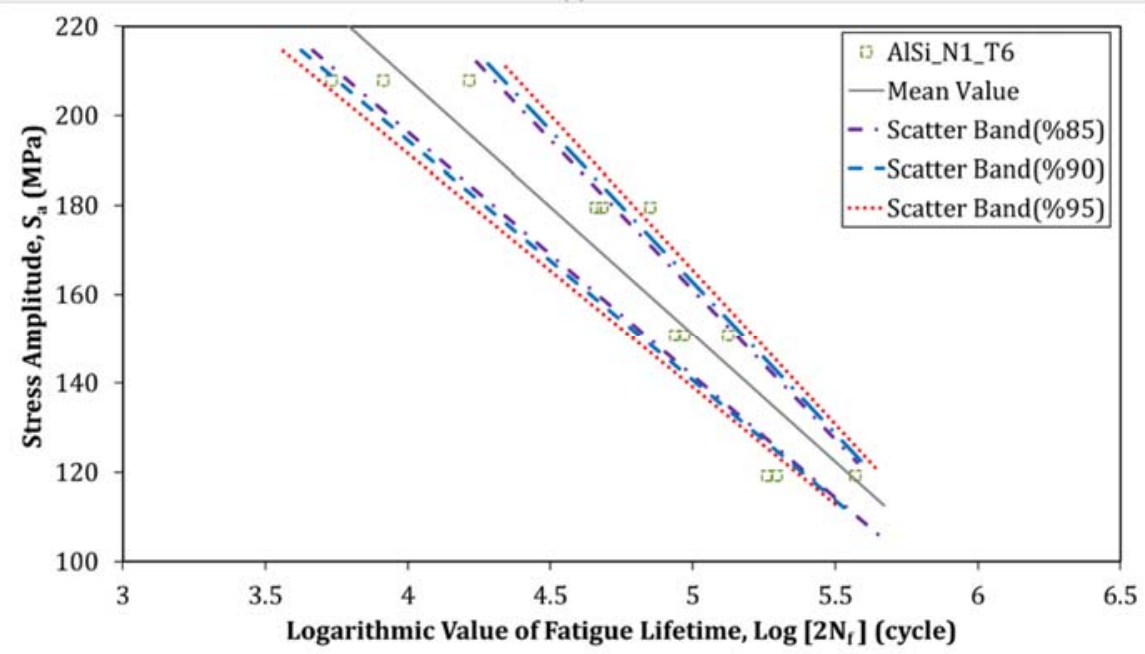

Figure 4: The scatter-band for corrosion-fatigue data of (a) the aluminum alloy, (b) the nano-composite, and (c) the heat-treated nanocomposite (Note: The horizontal axis includes the logarithmic value of the fatigue lifetime). 
As another result by comparing the scatter-band in both Figs. 3 and 4, it could be claimed that wider scattering data occurred and were obtained under fatigue testing. The scatter-band of corrosion-fatigue data was narrower since the root cause under the corrosive environment could be more. The corrosion pits could increase the probability of the damage, in addition to the failure of the crack initiation due to mechanical loading and the maximum bending stress on the sample surface. Therefore, a higher probability of damages under corrosion-fatigue testing led to a narrower scatter-band, compared to that of pure fatigue testing on studied materials, as all detrimental conditions.

However, as a beneficial condition, nano-clay-particles decreased the scatter-band of experimental data for fatigue and corrosion-fatigue testing. This could be due to finer grains in the material microstructure, as reported in the literature [10]. Against such a description, Morel et al. [18] showed that the microstructure and the defect could reflect the scatter-band, observed in the fatigue strength of metallic materials. This scatter-band is often explained by the anisotropic behavior of the material. Shlyannikov et al. [19] found that there was a steady relationship between the crack growth rate and the plastic stress intensity factor in the form of the general curve, within a relatively narrow scatter-band for all tested specimens of 2024 and 7075 aluminum alloys, at different temperatures.

As another reason, Farzannasab et al. [20] illustrated that results usually have had remarkable scatter-bands, due to the lack of repeatability of testing. In other words, the number of fatigue testing could influence the scatter-bank analysis. In the present work, 4 stress levels were considered for bending fatigue testing under 120, 150, 180, and $210 \mathrm{MPa}$. Moreover, under each stress level, 3 samples were tested. If the number of such a test with similar loading conditions increases, the scatter-band would be changed for the studied materials.

One way to have a deep investigation on the scatter-band is to analyze the microstructure of the material. Since the obtained trends could be attributed to the microstructure of the studied aluminum alloy. In addition, the effect of the nano-particles addition or the applied heat treatment could be found from the microstructure. Moreover, the role of casting defects could not be ignored for their influences on the scatter-band of the fatigue lifetime. In this regard and for some cases, the microstructural study of the material was presented in the literature [8].

For further investigations and in order to continue this work, the failure probability could be calculated, in addition to the reliability [21] for each stress level. This job could be done for various distribution functions including Normal, Weibull, extreme maximum value (EMV), and smallest extreme value (SEV) distributions [20]. Then, the probability density function (PDF) could be obtained based on the distribution function and the cumulative distribution function (CDF), and also the reliability could be calculated for failures.

\section{CONCLUSIONS}

$\mathrm{I}$

n the present article, the sensitivity analysis was performed for the stress, the pre-corrosion, nano-particles, and the heat treatment on the fatigue lifetime of aluminum alloys. Obtained results could be highlighted as follows,

- Fatigue and fatigue-corrosion lifetimes of the aluminum alloy, reinforced with nano-particles and the heat treatment process increased by 128 and $114 \%$, respectively, under high-stress levels, compared to the base aluminum alloy. However, under low-stress levels and through the high-cycle fatigue regime, such a behavior was not observed.

- The reduction in the fatigue lifetime was significant for 200 hours of immersion time, especially through the highcycle fatigue regime, which equaled lower stress levels. The reason was due to the surface damage and pits caused by corrosion reactions.

- When the normal scale of the fatigue lifetime was considered, reinforcing parameters were not effective. However, all four parameters of the stress, the pre-corrosion, the addition of nano-particles to the aluminum matrix and the heat treatment had effects on the logarithmic scale of the fatigue lifetime of studied materials.

- The scatter-band analysis revealed that the addition of nano-particles and the heat treatment could change the scatter-band of fatigue and corrosion-fatigue experimental data, compared to the aluminum alloy. That is due to the probable defects during the stir-casting process.

\section{ACKNOWLEDGEMENT}

uthors would tend to acknowledge Motorsazi Pooya Neyestanak (MPN) Company, located in Isfahan, Iran for providing raw materials and also Dr. Mahboobed Azadi at Semnan University for the scientific support on this research. 


\section{REFERENCES}

[1] Aroo, H., Azadi M., Azadi, M. (2021). Corrosion effects on high-cycle fatigue lifetime and fracture behavior for heattreated aluminum-matrix nano-clay-composite compared to piston aluminum alloy. Silicon. DOI: $10.1007 / \mathrm{s} 12633-021-01129-\mathrm{w}$.

[2] Azadi, M., Aroo, H., Azadi, M., Parast, M.S.A. (2021). Comparing of high-cycle fatigue lifetimes in un-corroded and corroded piston aluminum alloys in diesel engine application. Archives of Foundry Engineering, 21, pp. 89-94. DOI: $10.24425 /$ afe.2021.136083.

[3] Azadi, M., Zomorodipour M., Fereidoon, A. (2021). Sensitivity analysis of mechanical properties and ductile/brittle behaviors in aluminum-silicon alloy to loading rate and nano-particles, considering interaction effects. Engineering Reports, 3(6), e12341. DOI: 10.1002/eng2.12341.

[4] Guerin, M., Alexis, J., Andrieu, E., Blanc, C., Odemer, G. (2015). Corrosion-fatigue lifetime of Aluminum-CopperLithium alloy 2050 in chloride solution. Materials and Design, 87, pp. 681-69. DOI: 10.1016/j.matdes.2015.08.003.

[5] Chen, Y., Zhou, J., Liu, C., Wang, F. (2018). Effect of pre-deformation on the pre-corrosion multiaxial fatigue behaviors of 2024-T4 aluminum alloy. International Journal of Fatigue, 108, pp. 35-46. DOI: 10.1016/j.ijfatigue.2017.11.008.

[6] Rodriguez, R.I., Jordon, J.B., Allison, P.G., Rushing, T., Garcia, L. (2019). Corrosion effects on fatigue behavior of dissimilar friction stir welding of high-strength aluminum alloys. Material Science and Engineering A, 742, pp. 255268. DOI: 10.1016/j.msea.2018.11.020.

[7] Azadi, M., Aroo, H. (2021). Sensitivity analysis of stress, pre-corrosion, nano-particles and heat treatment on fatigue lifetime of aluminum alloy. Structural Integrity Procedia, IGF26 - 26th International Conference on Fracture and Structural Integrity.

[8] Azadi, M., Bahmanabadi, H., Gruen, F., Winter, G. (2020). Evaluation of tensile and low-cycle fatigue properties at elevated temperatures in piston aluminum-silicon alloys with and without nano-clay-particles and heat treatment. Materials Science and Engineering A, 788, 139497. DOI: 10.1016/j.msea.2020.139497.

[9] Metallic materials - Rotating bar bending fatigue testing, (2010). ISO-1143:2010 Standard, Available at: https://www.iso.org/standard/41875.html.

[10] Rezanezhad, S., Azadi, M., Azadi, M. (2021). Influence of heat treatment on high-cycle fatigue and fracture behaviors of piston aluminum alloy under fully-reversed cyclic bending. Metals and Materials International, 27, pp. 860-870. DOI: 10.1007/s12540-019-00498-7.

[11]Zolfaghari, M., Azadi, M., Azadi, M. (2021). Characterization of high-cycle bending fatigue behaviors for piston aluminum matrix $\mathrm{SiO}_{2}$ nano-composites in comparison to aluminum-silicon alloys. International Journal of Metalcasting, 15, pp. 152-168. DOI: 10.1007/s40962-020-00437-y.

[12] Parast, M.S.A., Khameneh, M.J., Azadi, M., Azadi, M., Mahdipanah M.H., Roostaie, S. (2021). Effect of plasma nitriding on high-cycle fatigue properties and fracture behaviors of GJS700 nodular cast iron under cyclic bending loading. Fatigue and Fracture of Engineering Materials and Structures, 44(8), pp. 2070-2086. DOI: 10.1111/ffe.13479.

[13] Sharifi, M.J., Azadi, M., Azadi, M. (2020). Fabrication of heat-treated nano-clay-composite for improving high-cycle fatigue properties of $\mathrm{AlSiCu}$ aluminum alloy under stress-controlled fully-reversed bending loads. Proceedings of the Institution of Mechanical Engineers, Part C: Journal of Mechanical Engineering Science.

DOI: $10.1177 / 0954406220969731$.

[14] Khisheh, S., Khalili, K., Azadi, M., Hendouabadi, V.Z. (2021). Influences of roughness and heat treatment on highcycle bending fatigue properties of A380 aluminum alloy under stress-controlled cyclic loading. Materials Chemistry and Physics, 264, 124475. DOI: 10.1016/j.matchemphys.2021.124475.

[15] Zhai, J.M., Li, X.Y. (2012). A methodology to determine a conditional probability density distribution surface from S$\mathrm{N}$ data. International Journal of Fatigue, 44, pp. 107-115. DOI: 10.1016/j.ijfatigue.2012.05.008.

[16] Khameneh, M.J., Azadi, M. (2018). Reliability prediction, scatter-band analysis and fatigue limit assessment of highcycle fatigue properties in EN-GJS700-2 ductile cast iron. MATEC Web of Conferences, $12^{\text {th }}$ International Fatigue Congress, 165, 10012. DOI: 10.1051/matecconf/201816510012.

[17] Lee, Y.L., Pan, J., Hathaway, R., Barkey, M. (2004). Fatigue testing and analysis. John Wiley and Sons, USA.

[18] Morel, F., Guerchais, R., Saintier, N. (2015). Competition between microstructure and defect in multiaxial high cycle fatigue. Fracture and Structural Integrity, 33, pp. 404-414. DOI: 10.3221/IGF-ESIS.33.45.

[19] Shlyannikov, V., Yarullin, R., Ishtyryakov, I. (2017). Effect of different environmental conditions on surface crack growth in aluminum alloys. Fracture and Structural Integrity, 41, pp. 31-39. DOI: 10.3221/IGF-ESIS.41.05. 
[20] Farzannasab, M., Azadi, M., Bahmanabadi, H. (2020). Study of high-cycle fatigue properties in bovine tibia bones based on reliability and scatter-band predictions. Mechanics of Advanced Composite Structures, 7(2), pp. 255-261. DOI: 10.22075/MACS.2019.18248.1215.

[21] Yang, G. (2007). Life cycle reliability engineering. John Wiley and Sons, USA. 